\title{
Decoupled Control of Active and Reactive Power for a Grid-connected Doubly-fed Wound Rotor Induction Machine without Position Sensors
}

\author{
Rajib Datta, Student Member, IEEE and V. T. Ranganathan, Senior Member, IEEE \\ Department of Electrical Engineering \\ Indian Institute of Science \\ Bangalore 560 012, INDIA \\ rdatta@ee.iisc.ernet.in vtran@ee.iisc.ernet.in
}

\begin{abstract}
In this paper field-oriented control of a doubly-fed wound rotor induction machine without shaft position sensors is presented. The stator is directly connected to the constant frequency three phase grid and the rotor currents are appropriately controlled to vary the slip power thereby enabling variable speed constant frequency operation. Instead of using dynamic angle controllers for rotor position estimation, a direct method based on simple transformations is proposed. The control algorithms are implemented on a DSP-based hardware platform and tested on a laboratory motor-generator set. Details of the algorithms, implementation, and relevant experimental results are presented.
\end{abstract}

\section{NOMENCLATURE}

$\underline{u}_{s}, \underline{i}_{s} \quad$ Stator voltage and current vectors

$\underline{i}_{m s} \quad$ Stator flux magnetizing current vector

$\underline{u}_{r} \quad$ Rotor voltage vector

$\underline{i}_{r} \quad$ Rotor current vector in rotor reference frame

$\underline{i}_{r}{ }^{s} \quad$ Rotor current vector in stator reference frame

$\underline{u}_{a c} \quad$ Transformer secondary voltage vector

$\underline{u}_{f e} \quad$ Terminal voltage vector of front-end converter

$i_{f e}, i_{g} \quad$ Front-end converter and grid current vectors

$\omega_{s}, \omega_{m s}, \omega$ Supply, stator flux, rotor angular frequency

$L_{s}, L_{n}, L_{0} \quad$ Stator, rotor and magnetizing inductance ${ }^{1}$

$R_{s}, R_{r} \quad$ Stator, rotor resistance ${ }^{1}$

$T_{r} \quad$ Rotor time constant

$\sigma_{s}, \sigma_{n} \sigma$ Stator leakage, rotor leakage, leakage factor

$L_{f e} \quad$ AC side inductance of front-end converter

$G_{r}, G_{f e} \quad$ Rotor-side converter, front-end converter gain

$\varepsilon \quad$ Angle between stator and rotor axes

$\mu \quad$ Angle between stator and field axes

$\rho_{l} \quad$ Angle between $\underline{i}_{r}$ and stator axis

$\rho_{2} \quad$ Angle between $\underline{i}_{r}$ and rotor axis

$\theta \quad$ Angle between $\underline{u}_{s}$ and stator axis

$K_{p n} K_{p f e} \quad$ Proportional gain for rotor-side, front-end current control

$K_{i n}, K_{i f e} \quad$ Integral gain for rotor-side, front-end current control

Subscripts

$1,2,3 \quad 3$ phases

$\alpha, \beta \quad$ Coordinate system in stator reference frame

$a, b \quad$ Coordinate system in rotor reference frame

$d, q \quad$ Coordinate system in synchronous reference frame

Supercript ' Intermediate variable for position estimation

\footnotetext{
${ }^{1}$ Stator turns : Rotor turns $=1: 1$
}

\section{INTRODUCTION}

The doubly-fed wound rotor induction machine is an attractive alternative to cage rotor induction machines and synchronous machines in high power applications where the speed range is limited [1]. The stator is directly connected to the constant frequency three phase grid and the rotor currents are appropriately controlled to vary the slip power thereby enabling variable speed constant frequency operation. Since the control is exercised on the rotor side the power ratings of the converters are small. This configuration finds an interesting application in wind-electric generation where the major challenge is independent control of active and reactive powers, so that maximum energy can be harnessed from the wind; simultaneously the operating power factor is to be maintained high irrespective of the generating conditions [2]. The physical separation between the electric generator (which is coupled to the turbine shaft through gears) and the power electronic converters (which are at ground level) requires minimal interface between the two and, therefore, for higher reliability demands control without shaft position sensors. Unlike the existing methods of sensorless control $[3,4]$ which employ rotor voltage integration or inverse function, a direct method based on simple transformations is proposed. The control algorithms are implemented on a TMS320F240 DSPbased hardware platform and tested on a laboratory motorgenerator set. In this paper, the details of the algorithms for decoupled control of active and reactive power and sensorless operation are discussed. Issues regarding practical implementation are highlighted and the relevant experimental results pertaining to generator operation are presented.

\section{SYSTEM OVERVIEW AND EXPERIMENTAL SETUP}

The schematic of the experimental setup is given in Fig.1. The stator of the wound rotor machine is connected to the balanced three phase grid and the rotor side is fed via two back-to-back IGBT voltage source inverters with a common dc bus. Since the speed range is restricted, the slip induced voltage is only a fraction of the grid voltage. Therefore, the dc bus voltage is kept relatively low. In the experimental setup it is maintained at $300 \mathrm{~V}$ for a slip range of 0.375 corresponding to a modulation index of 0.85 for the rotor side converter (The transient limit for modulation index is set to 0.9 [Appendix]). This necessitates a step-down transformer 


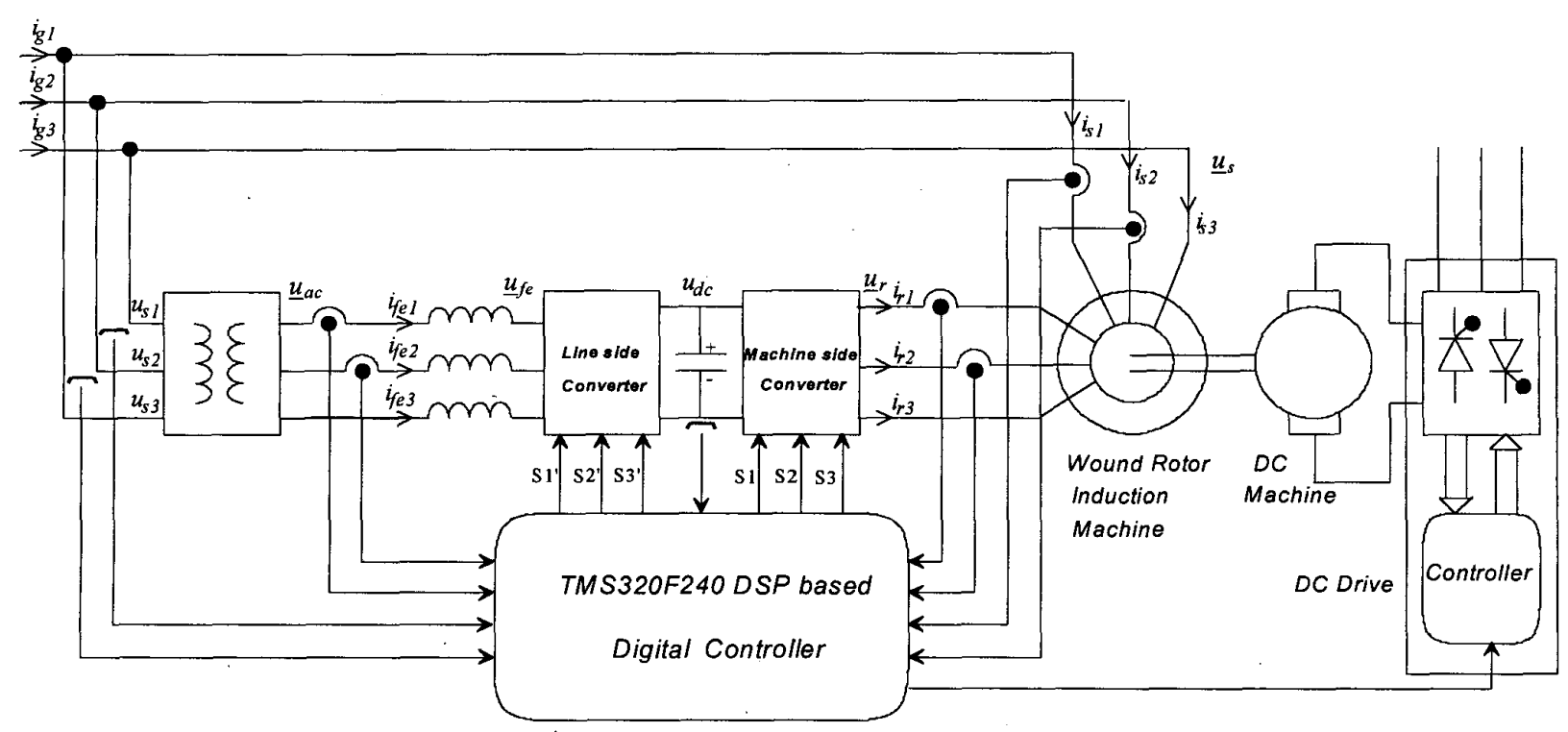

Fig.1 Schematic of the experimental setup

at the line-side interface. The front-end converter (FEC) controls the power flow between the dc bus and the ac side. It has the same three phase bridge topology and a control strategy almost identical to that of the rotor side converter. This back-to-back arrangement of two PWM converters with a common dc bus makes the system extremely flexible in terms of control of active and reactive power flow. The machine can now be operated in sub-synchronous and supersynchronous speeds because the rotor circuit is capable of sourcing and sinking the slip power. Even though the active power flow is proportional to the slip, the reactive power flow can be independently controlled for the machine side and line side converters; hence the overall system power factor can be kept at unity under varying conditions of load/input. The torque-speed characteristics of the prime mover/load is simulated in the laboratory by a dc machine run by a four-quadrant thyristor drive which can be operated either in the speed control or torque control mode.

\section{ROTOR SIDE CONTROL}

\section{A. Four quadrant operation through rotor side control}

The operating region of the system in the torque-speed plane is shown in Fig.2. Since the rotor side control strategy becomes advantageous within a limited slip range, the operating region is spread out on both sides of the synchronous speed $\omega_{s}$, implying both sub-synchronous and super-synchronous modes of motoring and generating operations. Based on the simplified equivalent circuit of Fig.3, the principle of operation for the generating modes i.e. Mode III and Mode IV (for which experimental results are furnished) is explained in this section with the help of the phasor diagram in Fig.4.

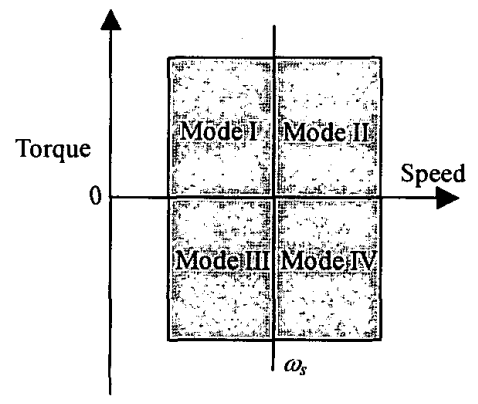

Fig.2 Operating region with rotor side control

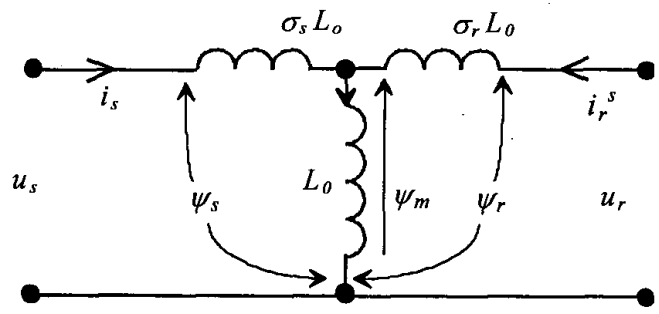

Fig.3 Approximate equivalent circuit

Assuming negligible stator resistance drop the stator flux $\psi_{s}$, and hence the stator flux magnetizing current $\underline{i}_{m s}$ [1], remain constant in magnitude lagging the stator voltage vector by $90^{\circ} e$. The magnitude of $i_{m s}$ can be defined as

$i_{m s}=\left(1+\sigma_{s}\right) i_{s d}+i_{r d}$

Since control is exercised on the rotor side an injection of positive $i_{r d}$ will naturally result in lesser value of $i_{s d}$ being 
drawn from the stator terminals leading to an improvement in the stator power factor in accordance with (1).

In the $q$-axis,

$$
0=\left(1+\sigma_{s}\right) i_{s q}+i_{r q}
$$

The magnitude of $i_{s q}$ being directly proportional to $i_{r q}$, the machine can be looked upon as a current transformer as far as the active power flow in the stator and the rotor are concerned. In the phasor diagram Fig.4, an injection of positive $i_{r q}$ implies that $i_{s q}$ is negative indicating active power flow into the grid at the stator terminals.

The locus of $\underline{i}_{s}$ and $\underline{i}_{r}^{s}$ for constant active power flow is shown in Fig.5. As the tip of the rotor current phasor is moved from $B$ ' to $A$ ', the stator current phasor locus moves in the opposite direction from $B$ to $A$. From this phasor diagram it may be appreciated that some amount of reactive power can as well be delivered to the source from the stator side, when the reactive power supplied from the rotor is more than the machine requirement. This is, however, possible when the active load demand is low and there is adequate current margin in the rotor coils. In order to utilize the copper in the stator and rotor circuits effectively, it is advisable to divide the reactive power demand between the two ports.

With $i_{r q}$ remaining positive if the machine is run above synchronous speed, it enters into super-synchronous generation (Mode IV). The phase relationships in this mode of operation remain unchanged in the stator reference frame compared to Mode III. But the induced voltage in the rotor circuit becomes negative (owing to negative slip) indicating reversal of rotor power.

The machine can similarly be operated in the motoring mode by forcing negative $i_{r q}$, thereby reversing the phase of $i_{s q}$. The direction of the rotor power flow depends on the speed of operation; the power flow being negative i.e. out of the rotor circuit for sub-synchronous motoring (Mode I) and

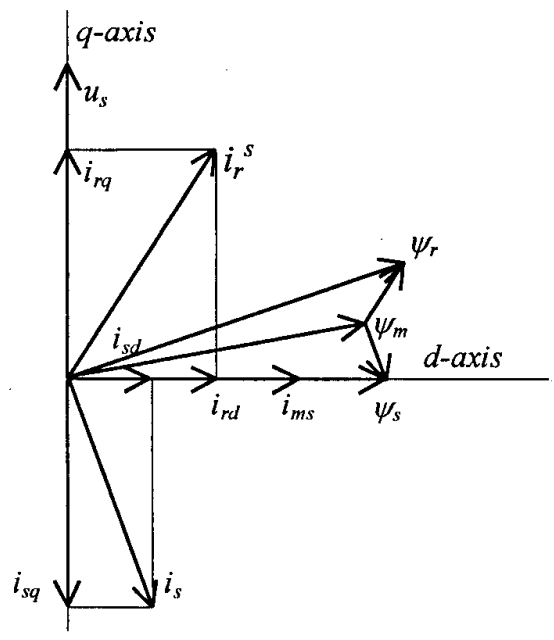

Fig.4. Phasor diagram for Mode III

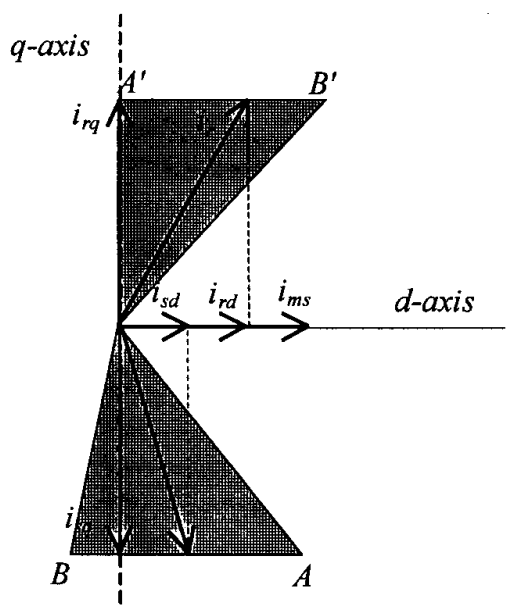

Fig. 5 Locus of $\underline{i}_{s}$ and $\underline{i}_{r}$ for change in $i_{r d}$

positive i.e. into the rotor for super-synchronous motoring (Mode II). It is interesting to note that in super-synchronous modes of operation the directions of stator and rotor powers are the same. Hence if the stator handles 1 p.u. of active power while the machine is running at a slip $s$, the total power generated/consumed will be $(1+s)$ p.u.

\section{B. Rotor Current Control}

From the above discussion it may be appreciated that for decoupled control of stator active and reactive powers the rotor currents need to be transformed to the stationary reference frame and oriented with respect to the stator flux. Since the stator flux is practically at quadrature with the supply voltage, orientation can be done with respect to the latter without any significant error or coupling. The governing equations for the rotor currents in the synchronous reference frame can be written as folows [4].

$$
\begin{gathered}
\sigma T_{r} \frac{d i_{r d}}{d t}+i_{r d}=\frac{u_{r d}}{R_{r}}+\left(\omega_{m s}-\omega\right) \sigma T_{r} i_{r q}-(1-\sigma) T_{r} \frac{d i_{m s}}{d t} \\
\begin{aligned}
\sigma T_{r} \frac{d i_{r q}}{d t}+i_{r q}= & \frac{u_{r q}}{R_{r}}-\left(\omega_{m s}-\omega\right) \sigma T_{r} i_{r d} \\
& -\left(\omega_{m s}-\omega\right)(1-\sigma) T_{r} i_{m s}
\end{aligned}
\end{gathered}
$$

It is observed that due to the presence of the rotational emf terms there is some cross-coupling between the $d$ and $q$ axes. The current loop dynamics along the two axes can be made independent of each other by compensating for these crosscoupling terms. However, as the slip range is limited the contributions of these terms are rather weak. Also the stator flux is practically constant and, therefore, the transformer emf term depending on its derivative in (3) can be ignored.

The rotor side controller block diagram is given in Fig.6. The references for the rotor currents $i_{r q}{ }^{*}$ and $i_{r d}{ }^{*}$ are derived from the active and reactive power references $P^{*}$ and $Q^{*}$ 


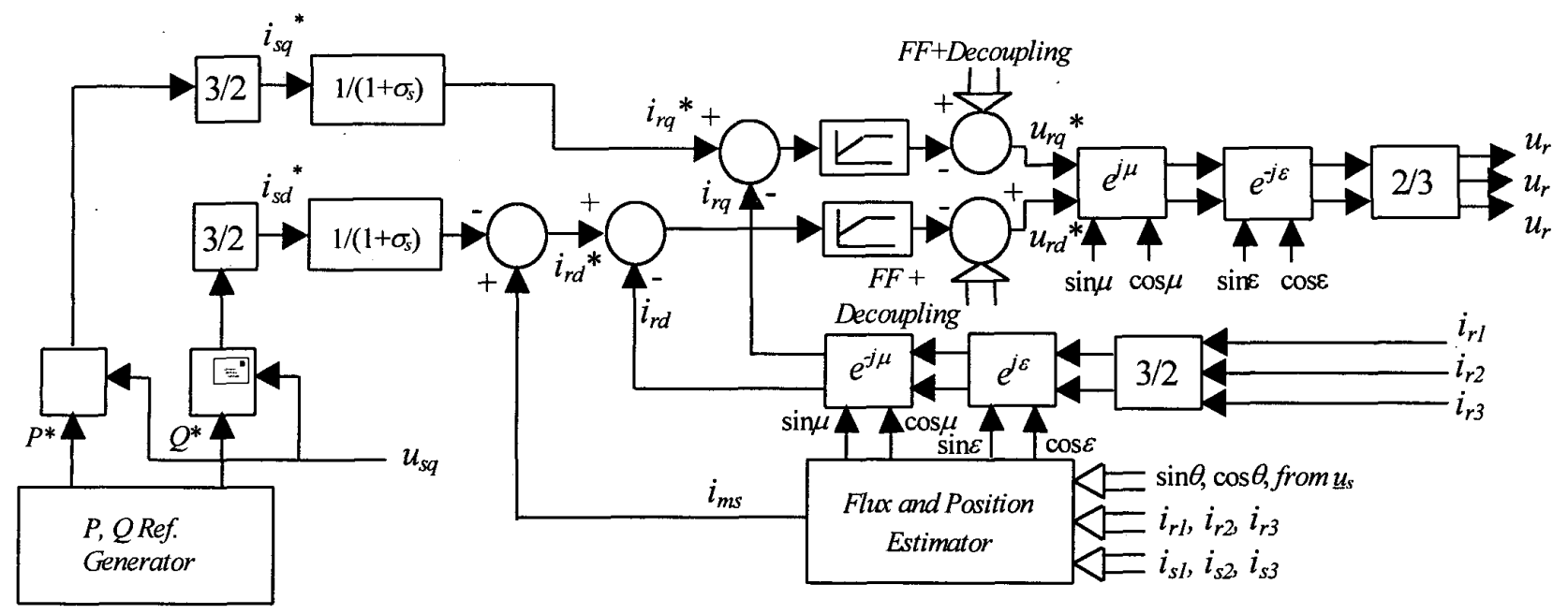

Fig.6 Block diagram of rotor side converter controller

respectively, which in turn can be dynamically varied depending on the specific application. (For example, in case of wind-power generation, $\mathrm{P}^{*}$ is made to vary as the cube of the rotor speed in order to operate in the maximum power transfer mode, unless the power limit is reached.) The rotor currents are first transformed to the stator coordinates $\left(e^{j}\right)$ and subsequently to the field coordinates $\left(e^{-j \mu}\right)$ to get $i_{r d}$ and $i_{r q}$. The control equations that determine the $d$-axis and $q$-axis inverter terminal voltage to get decoupled control of the rotor currents are as follows.

$$
\begin{aligned}
u_{r d}{ }^{*} & =\frac{1}{G_{r}}\left[\left(K_{p r}+K_{i r} \int\right)\left(i_{r d}{ }^{*}-i_{r d}\right)-\left(\omega_{m s}-\omega\right) \sigma L_{r} i_{r q}\right](5) \\
u_{r q}{ }^{*} & =\frac{1}{G_{r}}\left[\left(K_{p r}+K_{i r} \int\right)\left(i_{r q}{ }^{*}-i_{r q}\right)\right. \\
& \left.+(1-\sigma) L_{r}\left(\omega_{m s}-\omega\right) i_{m s}-\left(\omega_{m s}-\omega\right) \sigma L_{r} i_{r q}\right]
\end{aligned}
$$

These voltages are subsequently transformed back to the rotor reference frame $\left(\mathrm{e}^{j(\mu-\varepsilon)}\right)$ and modulated with a carrier triangle to generate the PWM patterns for the rotor side inverter.

\section{Position Estimation}

Proper orientation of the rotor currents with respect to the stator flux requires transformations between the stator and rotor coordinates for which the instantaneous rotor position information is necessary. Position sensorless method discussed in [2] uses a torque angle estimator by rotor voltage integration; hence estimation at or near synchronous speed is difficult. In [1], the angle between the rotor current vector and field axis is estimated using inverse tangent functions. The proposed method is based on simple trigonometric computations; therefore the estimation is instantaneous and it is possible to start the control on the fly without any appreciable transient.

The stator flux magnetizing current $i_{m s}$ depends on the stator voltage and frequency with a nominal magnitude of $\left|\underline{u}_{s}\right| /\left(\omega_{s} L_{o}\right)$. Also, the angle which $i_{m s}$ makes with the stator $\alpha$-axis (i.e. $\theta-90^{\circ}$ neglecting stator resistance) can be calculated from the stator voltage vector $\underline{u}_{s}$.

$i_{m s \alpha}=\left|i_{m s}\right| \cdot \sin \theta$

$i_{m s \beta}=-\left|i_{m s}\right| \cdot \cos \theta$

Using this value of $\underline{i}_{m s}$ and the measured value of $\underline{i}_{s}$, the rotor currents can be computed in the stationary coordinates as

$i_{r \alpha}=i_{m s \alpha}-\left(1+\sigma_{s}\right) i_{s \alpha}$
$i_{r \beta}=i_{m s \beta}-\left(1+\sigma_{s}\right) i_{s \beta}$

Therefore the unit vectors for $\underline{i}_{r}^{s}$ can be written as

$\cos \rho 1=i_{r \alpha} /\left|\underline{i_{r}^{s}}\right|$
$\sin \rho 1=i_{r \beta} /\left|\underline{i_{r}^{s}}\right|$

The rotor currents can also be directly measured in the rotor circuit and the unit vectors for $\underline{i}_{r}$ can be derived as

$\cos \rho 2=i_{r a} /\left|\underline{i_{r}}\right|$

$\sin \rho 2=i_{r b} /\left|\underline{i_{r}}\right|$

Equations (9), (10) and (11), (12) represent the unit vectors in two reference frames as shown in Fig. 7 ; the former rotating at synchronous speed and the latter at slip frequency. Therefore, the unit vectors pertaining to the rotor position $\varepsilon=(\rho 1-\rho 2)$ can be easily computed.

The accuracy of this computation mostly depends on the value of $\underline{i}_{m s}$ since the other quantities are directly measured. $i_{m s}$ may be computed by stator voltage integration so that variations in the ac bus voltage and frequency are taken into account. But it is also observed that at rated voltage, owing to 


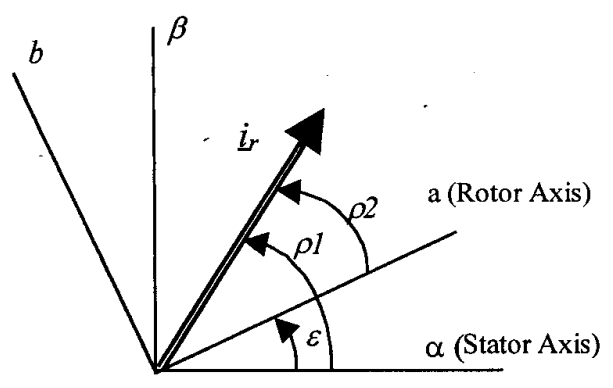

Fig.7 Rotor current vector in rotor and stator coordinates

saturation of the magnetic circuit, there is a slight boost in the $\underline{i}_{m s}$ value when reactive currents are injected from the rotor side. Any change in the magnitude of $\underline{i}_{m s}$ being much slower than the sampling frequency $(2.9 \mathrm{kHz}),\left|i_{m s}\right|$ can be correctly estimated by adopting the following method of recomputation. First, $\left|\underline{i}_{m s}\right|$ for the present sampling interval is computed by transforming the present rotor current sample to the stator coordinates with the unit vectors computed in the previous interval. This is furnished below.

$$
\begin{aligned}
& i_{r \alpha}{ }^{\prime}[k]=i_{r a}[k] \cdot \cos \varepsilon[k-1]-i_{r b}[k] \cdot \sin \varepsilon[k-1] \\
& i_{r \beta}{ }^{\prime}[k]=i_{r b}[k] \cdot \cos \varepsilon[k-1]+i_{r a}[k] \cdot \sin \varepsilon[k-1] \\
& i_{m s \alpha}{ }^{\prime}[k]=\left(1+\sigma_{s}\right) \cdot i_{s \alpha}[k]+i_{r \alpha}{ }^{\prime}[k] \\
& i_{m s \beta}{ }^{\prime}[k]=\left(1+\sigma_{s}\right) \cdot i_{s \beta}[k]+i_{r \beta}{ }^{\prime}[k]
\end{aligned}
$$

$\left|\underline{i}_{m s}\right|$ as calculated from (17) and (18) is passed through a first-order low-pass filter with $\tau_{L P}=1 \mathrm{~ms}$. This ensures that even if there is any small error in the previous sample of $\sin \varepsilon$ and $\cos \varepsilon$ it is not directly reflected in the present $\left|\underline{i}_{m s}\right|$ estimate. Subsequently using the stator voltage angle $\theta, i_{m s \alpha}$ and $i_{m s \beta}$ are recomputed using (7) and (8).

Therefore the computation starts with the nominal value of $\left|i_{m s}\right|$ for the first few sampling intervals and then switches over to this re-computation method. The estimation process thus becomes independent of variations in the stator voltage and frequency as well as machine parameters. The instantaneous nature of computation also ensures jitter-free estimation during transients in active and reactive power. It may be noted that the unit vectors $\sin \varepsilon$ and $\cos \varepsilon$ corresponding to the rotor position suffice for executing the vector control algorithm and the actual angle need not be computed through inverse functions.

\section{Speed Estimation}

The decoupling terms associated with the rotor current controller being slip dependent it is necessary to compute the speed of the machine. Apart from regular motor drive applications the speed information is also necessary for generation applications like wind-energy conversion systems where the active power reference is made to vary as a function of the rotor speed to achieve maximum power transfer. Here the per unit speed is computed by differentiation of the unit vectors as

$$
\begin{aligned}
\omega_{e s t}[k] & =[\cos \varepsilon[k] \cdot(\sin \varepsilon[k]-\sin \varepsilon[k-1]) \\
& -\sin \varepsilon[k] \cdot(\cos \varepsilon[k]-\cos \varepsilon[k-1])] / \frac{2 \pi T_{s}}{T_{b}}
\end{aligned}
$$

where $T_{s}$ is the sampling period $(342 \mu s)$ and $T_{b}$ is the base period ( $20 \mathrm{~ms}$ corresponding to $50 \mathrm{~Hz}$ ).

Even though the unit vectors are smoothly varying sinusoidal signals, the differential terms contribute some noise which is eliminated by employing a first-order low-pass filter. The position and speed estimation block diagrams are shown in Fig.8.

\section{FRONT-END CONVERTER CONTROL}

\section{A. Current and Voltage Control}

The control structure for the front-end converter is similar to that of the rotor side converter; the ac side currents being oriented with respect to the grid voltage space phasor for

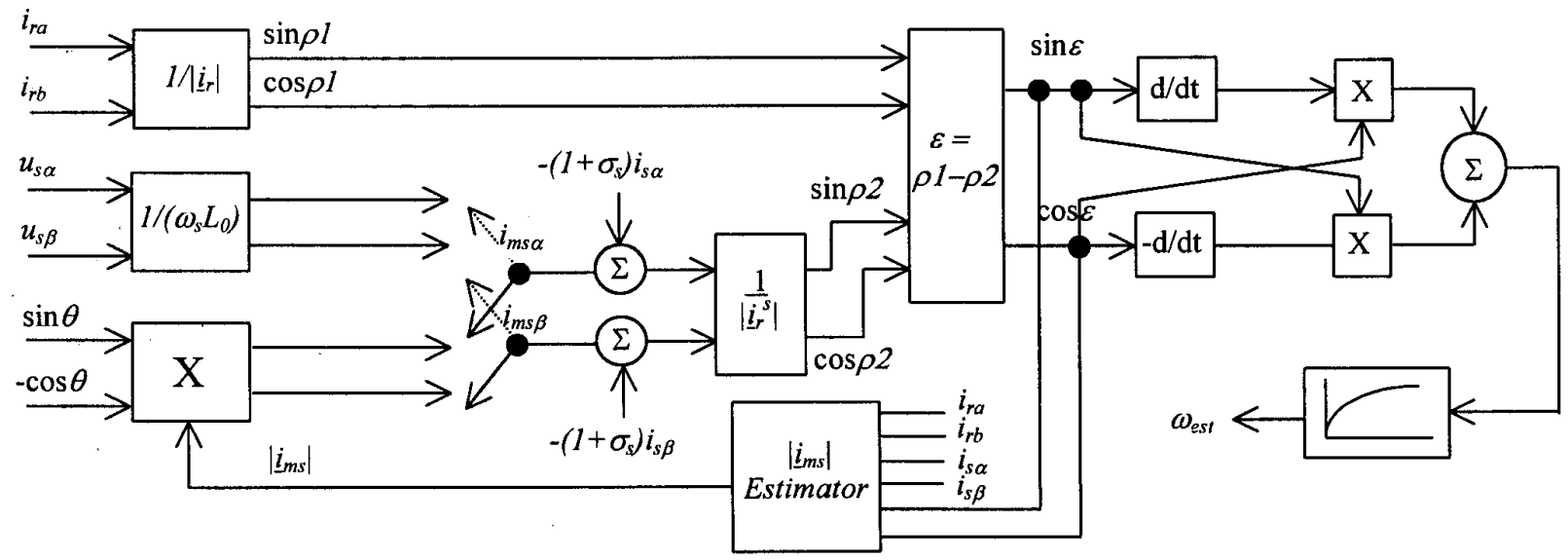

Fig.8 Block diagram of position and speed estimator 
decoupling the active and reactive components. The reference for the active current loop $i_{\text {feq }}{ }^{*}$ is derived from a dc bus voltage controller and the reference for the reactive loop $i_{\text {fed }}$ " is set according to the desired power factor. To maintain consistency in notations, the grid voltage vector direction is taken as the q-axis so that $i_{f e q}$ and $i_{\text {fed }}$ give the measure of active and reactive power flow respectively. Thus the equations governing the current loop dynamics in the two axes can be written as follows.

$L_{f e} \frac{d i_{f e d}}{d t}-\omega_{s} L_{f e} i_{f e q}+u_{f e d}=0$

$L_{f e} \frac{d i_{f e q}}{d t}+\omega_{s} L_{f e} i_{f e d}+u_{f e q}=u_{a c q}$

Therefore the rotational emfs which appear as crosscoupling terms due to the transformation and, the supply voltage which is essentially a disturbance input, have to be suitably compensated and fed-forward to produce proper decoupling between the axes and fast dynamic response.

The controller black diagram is given in Fig.9. The control equations for the active and reactive currents loops which determine the inverter voltage are as follows.

$$
\begin{aligned}
& \dot{u}_{f e q}^{*}=\frac{1}{G_{f e}}\left[-\left(K_{p f e}+K_{i f e} \int\right)\left(i_{f e q}^{*}-i_{f e q}\right)+\omega_{s} L_{f e} i_{f e d}+u_{a c q}\right](22) \\
& u_{f e d}^{*}=\frac{1}{G_{f e}}\left[-\left(K_{p f e}+K_{i f e} \int\right)\left(i_{f e d}^{*}-i_{f e d}\right)-\omega_{s} L_{f e} i_{f e q}\right]
\end{aligned}
$$

\section{B. Generation of Unit Vectors synchronized to the Grid}

The unit vectors for transformation of the inductor currents to the synchronous reference frame need to be synchronized to the ac bus. This is implemented by using a frequency tracker using internal 'F240 timers and is schematically illustrated in Fig.10. A general-purpose internal timer (GP Timer3) of the processor suitably clocked with a prescaled high speed clock and programmed in continuous up counting mode is used for determining the grid frequency. At every

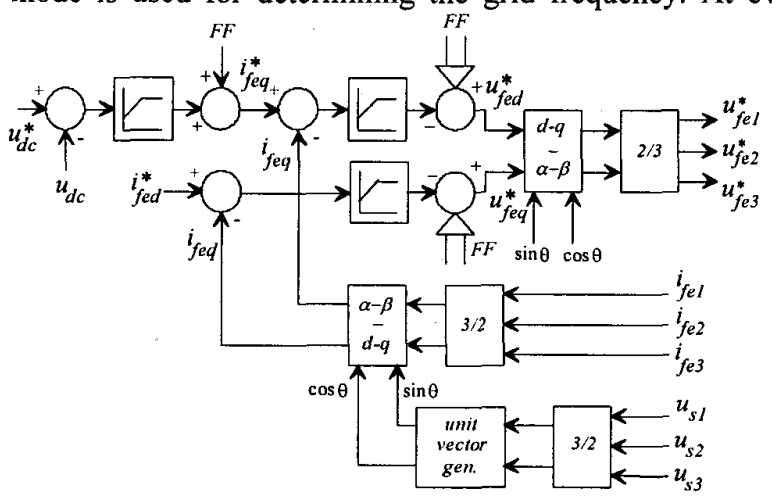

Fig.9 Block diagram of FEC controller

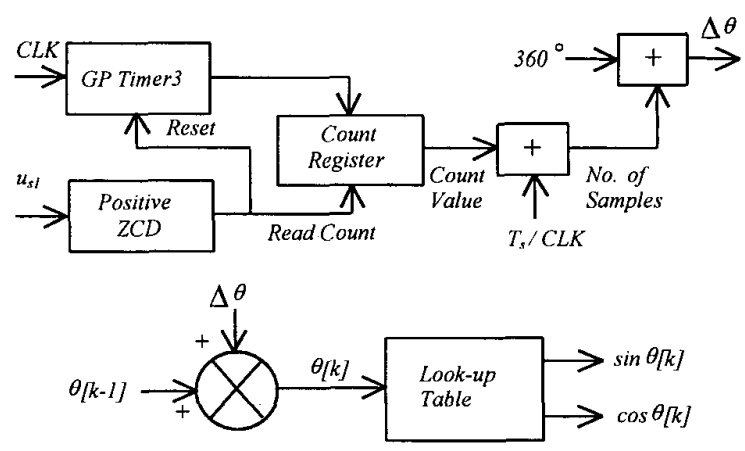

Fig.10 Schematic of unit vector synchronisation

positive zero crossing of the Phase A voltage the timer value is read off and reset to zero. This count is, therefore, proportional to the time period of the supply voltage for the previous cycle and is used to compute the increment in $\theta(\Delta \theta)$ at every sampling instant over the present cycle. With this estimated value of $\theta$ the unit vectors are then read off from a sine look-up table in the memory. Since the variation in grid frequency is slow this method ensures proper interlocking of the unit vectors with the supply voltage. It may be noted that if the unit vectors are derived directly from the phase voltages, the presence of harmonics results in their distortion in turn leading to distortion of the line current waveforms.

\section{EXPERIMENTAL RESULTS}

A TMS320F240 DSP based hardware platform operating at 36 MIPs has been developed for implementing the control algorithms. The software is organized for mutitasking with each time slot of $56 \mu$ s being assigned to the different tasks. The front-end current control loop is executed in every alternate slot $(112 \mu \mathrm{s})$ and is the fastest. All the other tasks namely rotor side flux and position estimation, rotor side current control, front-end voltage control, and generation of load/turbine characteristics for the dc drive are executed once in every $342 \mu \mathrm{s}$.

\section{A. Position and Speed Estimation}

A comparison between the unit vector $(\sin \varepsilon)$ generated using an incremental position encoder with $\sin \varepsilon$ computed employing the proposed sensorless method is given in Fig.11(a). The instantaneous tracking of the position ( when the rotor side control is activated ) and accurate steady-state estimation is observed. This is particularly important in generation applications like wind-power conversion where the machine has to be started on the fly when the turbine speed crosses the cut-in point. It is also observed in Fig.11(b) that a step change in $i_{r q}$ (active power reference) does not produce any transient in the estimation of $\sin \varepsilon$. The estimation of speed from $\sin \varepsilon$ and $\cos \varepsilon$ during starting is shown in Fig.11(c). During $T_{\text {rise }}$, the estimated speed has a 


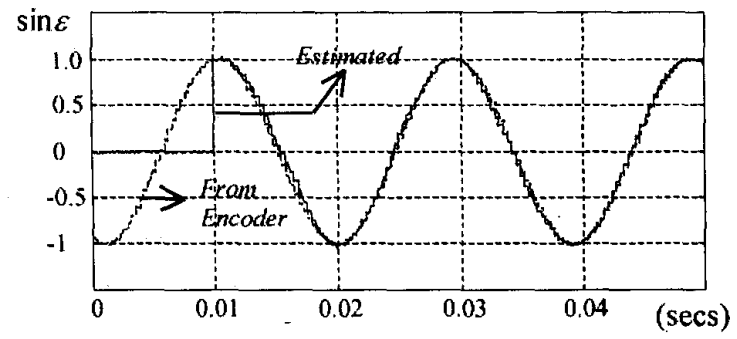

Fig. 11 (a) Actual and estimated position during starting.

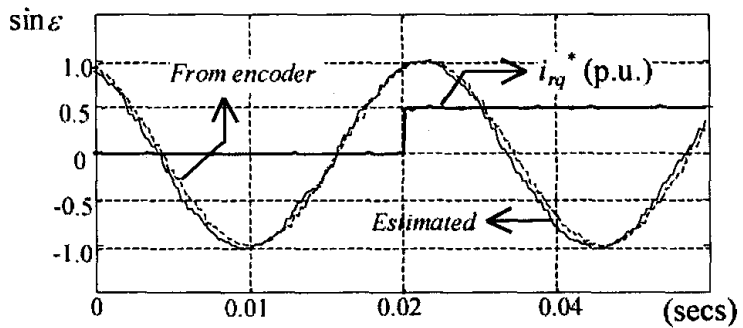

Fig.11(b) Actual and estimated position during $i_{r q}$ transient.

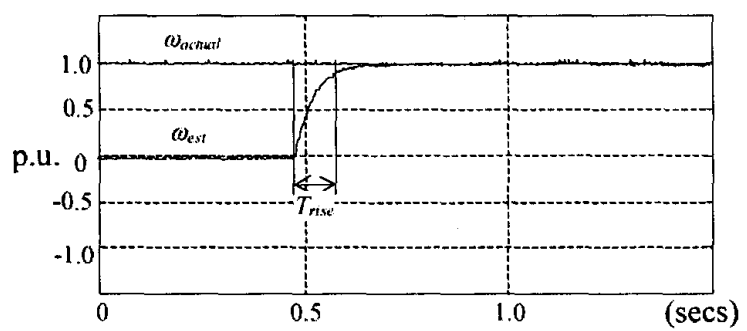

Fig. $11(\mathrm{c})$ Actual and estimated speed during starting.

large error and the slip-dependent decoupling terms will result in undesired transients and, in turn, erroneuos estimation. Hence, during starting the computed slip is forced to zero for about $100 \mathrm{~ms}$ ( 4 times the low-pass filter time constant)

\section{B. Rotor Side Control}

Fig.12(a) shows the transient response in $i_{r l}$ and $i_{r q}$ when the rotor side converter is switched on with the total reactive power being supplied from the rotor end and $i_{r q}{ }^{*}=0$. This corresponds to the stator being floated on the bus with zero current. Transient due to a step change in $i_{n j}{ }^{*}$ with constant $i_{n i}^{*}$ is shown in Fig. 12(b). If $i_{n i}^{*}$ reference is made equal to the magnetizing current after passing $\left|i_{\mathrm{ms}}\right|$ through a low pass filter, the reactive power can be fully supplied from the rotor side. The instantaneous active and reactive power waveforms at the stator terminals for step change in $P^{*}$ are given in Fig.12(c) to illustrate this fact. The decoupled nature of control is evident from these traces.

The steady-state voltage and current waveforms on the stator side are shown in Fig. 13(a). $\underline{i}_{r}^{s}$ is seen to be lagging $\underline{u}_{\text {. }}$ indicating reactive power being supplied from the rotor. It

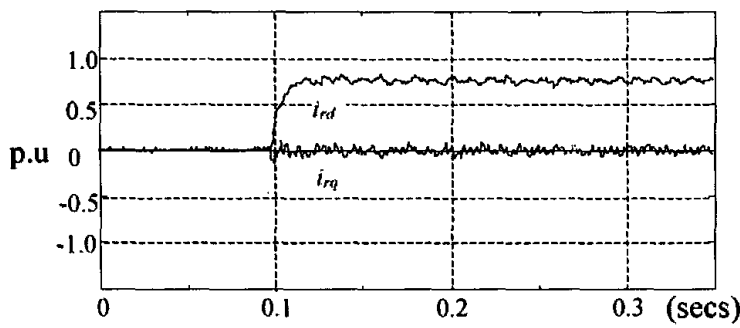

Fig. 12(a) $i_{n d}$ and $i_{r q}$ for step change in $i_{r d}{ }^{*}(0$ to 0.75 p.u. $)$

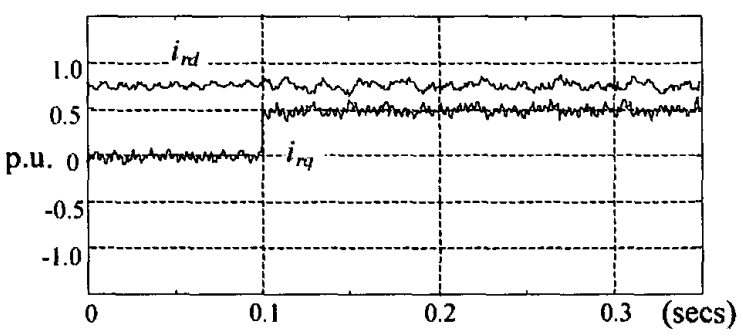

Fig.12(b) $i_{n d}$ and $i_{n q}$ for step change in $i_{r q}{ }^{*}(0$ to 0.5 p.u.)

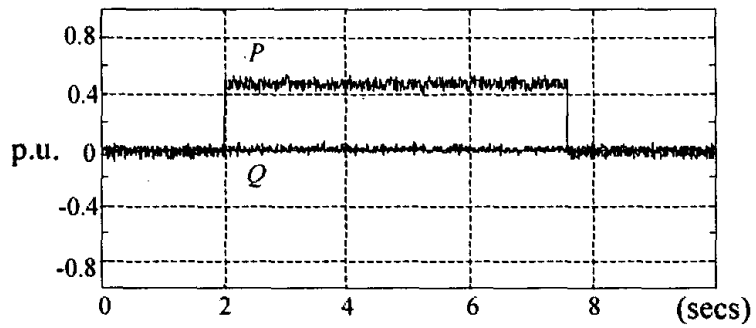

Fig. 12(c) $P$ and $Q$ for step change in $P^{*}$ (0 to 0.5 p.u.)

may be noted that seen from stator side the phase relations between the different currents do not change from subsynchronous to super-synchronous speed. Fig.13(b) illustrates steady-state operation at synchronous speed with $\underline{i}_{r}^{r}$ being the dc current injected onto the rotor circuit. As the rotor moves over synchronous speed the rotor current space phasor starts rotating in the opposite direction in the rotor reference frame indicating a change in phase sequence. This is noted in the rotor current waveform in Fig.13(c).

\section{Front-end Converter}

The front end converter is either operated at unity power factor or at a leading power factor. The steady-state unity power factor operation at sub-synchronous speed (power being fed into the rotor) is illustrated in Fig.14(a). The reactive power for the slip-ring machine may be partially supplied from the rotor and partially from the stator so that the stator power factor is improved. The front-end now can be operated at a leading power factor to compensate for balance amount of reactive power to some extent. Fig.14(b) illustrates the grid voltage and various current waveforms to illustrate such a situation. (The distortion in the grid current 


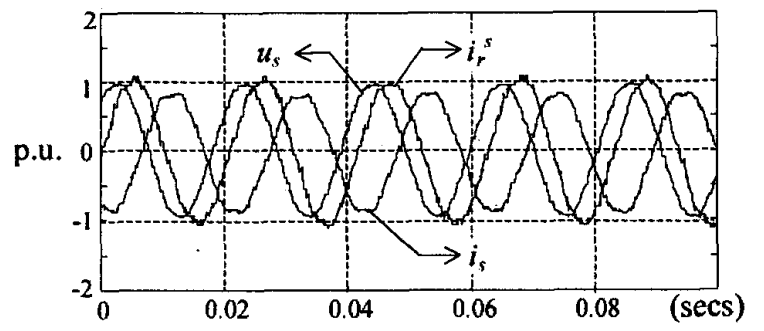

Fig.13(a) Steady-state plots of $u_{s,}, i_{s}, i_{r}^{s}$ for upf generation

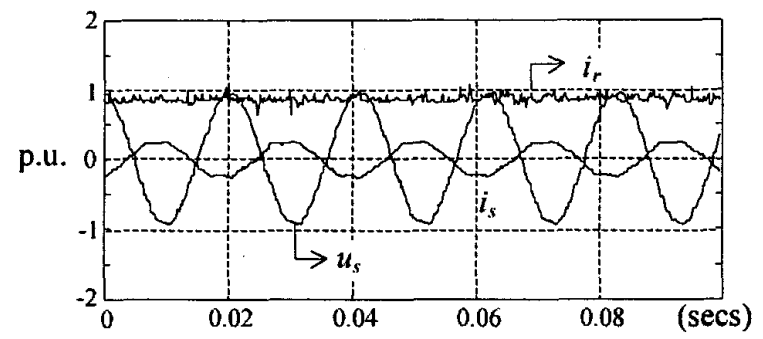

Fig.13(b) Steady-state plots of $u_{s}, i_{s}, i_{r}$ at synchronous speed.

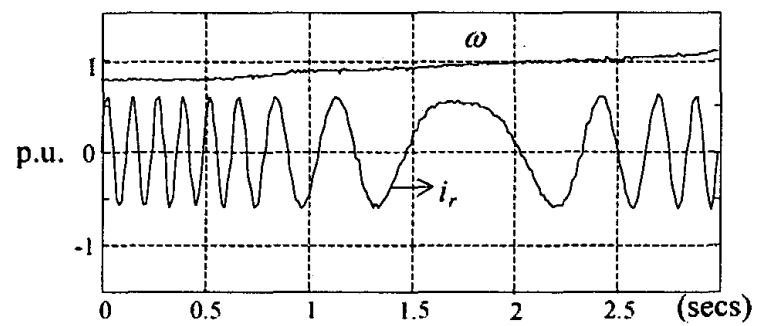

Fig.13(c) Transition through synchronous speed

waveform is due to magnetic saturation in the machine, which slightly distorts the stator current.) When positive active load is suddenly applied ( 0 to full load) the transient dip in the dc bus voltage from its nominal value of $300 \mathrm{~V}$ along with $i_{f e q}$ shown in Fig.14(c).

\section{CONCLUSION}

The proposed position estimation algorithm results in instantaneous and accurate tracking, and can be easily implemented. Decoupled control of active and reactive powers for the rotor side and front-end converters under transient and steady-state conditions is demonstrated. The presented scheme is a viable alternative to cage-rotor induction generators for variable-speed wind energy application.

\section{APPENDIX}

Slip-ring Induction machine

Rated power: $3 \mathrm{~kW}$

Stator: $415 \mathrm{~V}, \Delta$ connected, $7.2 \mathrm{~A}$

Rotor: $415 \mathrm{~V}, \mathrm{Y}$ connected, $6.6 \mathrm{~A}$

$R_{s}=1.557 \Omega, R_{r}=2.62 \Omega, L_{\theta}=177 \mathrm{mH}, \sigma_{s}=\sigma_{r}=0.1017$

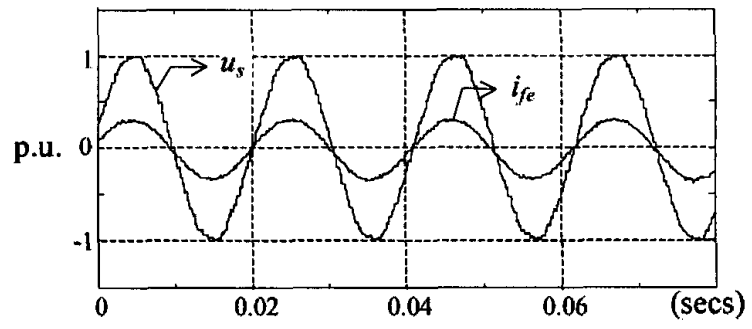

Fig. 14(a) Upf operation of FEC at sub-synchronous speed

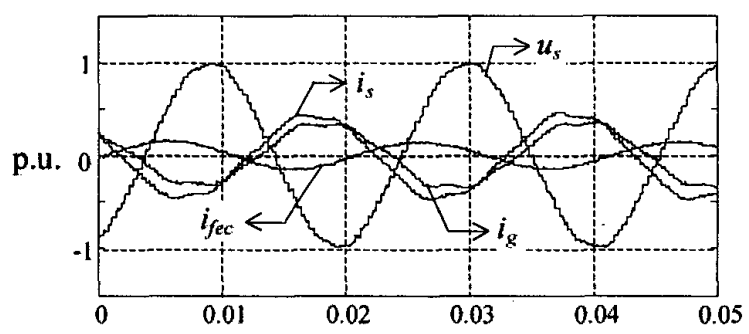

Fig. 14(b) $u_{s}, i_{s}, i_{f e}, i_{g}$ when FEC is operated at leading pf.

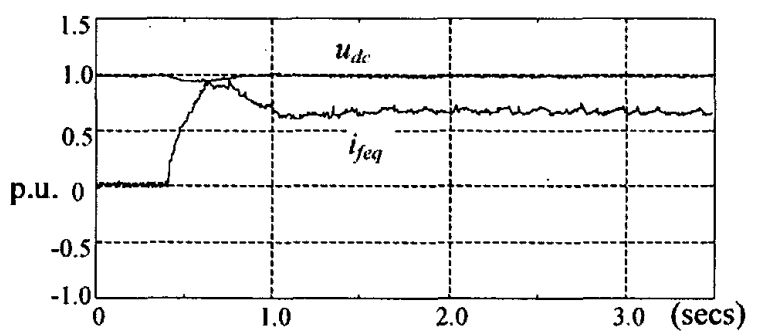

Fig. 14(c) Dip in $u_{d c}$ for step change in load ( 0 to 0.7 p.u.)

\section{Front-end Converter}

Transformer turns ratio: $415 \mathrm{~V}: 125 \mathrm{~V}$

Line side inductance: $17.5 \mathrm{mH} / \mathrm{ph}$ ase

DC link capacitance: $4000 \mu \mathrm{F}$

DC link voltage: $300 \mathrm{~V}$

\section{REFERENCES}

[1] W.Leonhard, "Control of Electric Drives," (SpringerVerlag, 1985).

[2] R.Pena, J.C.Clare, G.M.Asher, "Doubly fed induction generator using back-to-back PWM converters and its application to variable-speed wind-energy generation," IEE Proc.-Electr. Power Appl., Vol.143, No.3, May 1996, pp 231-241.

[3] W.Cheng, L.Xu, "Torque and Reactive Power Control of a Doubly-Fed Induction Machine by Position Sensorless Scheme," IEEE/LAS Trans., Vol.31, No.3, May/June 1995, pp 636-642.

[4] L.Morel, H.Godfroid, A.Mirzaian, J.M.Kauffmann, "Double-fed induction machine: converter optimisation and field oriented control without position sensor," IEE Proc.-Electr. Power Appl., Vol.145, No.4, July 1998, pp 360-368. 